\title{
Prospecção fitoquímica preliminar de plantas nativas do cerrado de uso popular medicinal pela comunidade rural do assentamento vale verde - Tocantins
}

\author{
BESSA, N.G.F.de ${ }^{1,2^{*}}$; BORGES, J.C.M. ${ }^{2}$; BESERRA, F.P. ${ }^{2}$; CARVALHO, R.H.A. ${ }^{2}$; PEREIRA, M.A.B. ${ }^{2}$; \\ FAGUNDES, R. ${ }^{2}$; CAMPOS, S.L. ${ }^{2}$; RIBEIRO, L.U²; QUIRINO, M.S ${ }^{2}$; CHAGAS JUNIOR, A. ${ }^{3}$; ALVES, ${ }^{4}$. \\ ${ }^{1}$ Doutoranda em Biologia e Ecologia Tropical, Departamento de Biologia, Universidade de Aveiro, Portugal/UFT/ \\ Ecotropical/Governo do Estado, Tocantins, Brasil. ${ }^{2}$ Fundação Centro Universitário UnirG, Av: Rio de Janeiro, \\ 1585, CEP: 77400-000 Gurupi, Tocantins, Brasil, e-mail*: eduambiental@unirg.edu.br. ${ }^{3}$ Universidade Federal \\ do Tocantins, Rua Badejós, Lt. 7, Chácara 69/72, CEP: 77402-970, Gurupi, Tocantins, Brasil. \\ ${ }^{4}$ Departamento de Biologia e CESAM, Universidade de Aveiro, CEP: 3810-193, Aveiro, Portugal.
}

\begin{abstract}
RESUMO: Este estudo objetivou caracterizar qualitativamente grupos de metabólitos secundários e alguns constituintes de 9 espécies de plantas medicinais nativas do cerrado utilizadas pela comunidade rural do Assentamento Vale Verde, identificando potencialidades biológicas e farmacológicas. As informações referentes às plantas de uso medicinal foram obtidas por meio de estudos etnobotânicos e etnofarmacológicos, realizados no período de 2010 a 2012. O material botânico coletado foi identificado e depositado no Herbário da Universidade Federal do Tocantins, Porto Nacional (TO). O extrato etanólico e metanólico foi obtido a partir do material seco em estufa, filtrado e concentrado em evaporador rotatório sob pressão reduzida, pesados e novamente colocados em estufa por $24 \mathrm{~h}$ a $50^{\circ} \mathrm{C}$, obtendo o rendimento $(\mathrm{m} / \mathrm{m})$ resultante da relação entre a massa de extrato concentrado e após seco. A análise fitoquímica das plantas selecionadas foi feita usando a metodologia da Prospecção Preliminar, realizando testes para detecção de alguns constituintes importantes e dos principais grupos de metabólitos: saponinas, fenóis e taninos, catequinas, esteróides e triterpenóides, cumarinas, antraquinonas e flavonóides. Os testes foram considerados positivos através de reações de precipitados com colorações, formações de espumas e manchas coloridas. Os testes fitoquímicos realizados nos extratos revelarem a presença de constituintes do metabolismo secundário das plantas que podem contribuir para a identificação de marcadores químicos para as espécies estudadas, sendo estes indispensáveis para os testes de qualidade e integridade de fitoterápicos e uso popular mais seguro das plantas medicinais, possibilitando melhor controle farmacognóstico dessas espécies e direcionamento dos seus usos e aplicações na pesquisa pela bioatividade preliminarmente conhecida. Neste caso, especialmente devido às atividades antimicrobianas, antioxidantes e contra insetos, sugerindo relação com a presença de compostos fenólicos e flavonoídicos, positivos nos extratos da maioria das espécies. Estas informações são inéditas no Tocantins e estratégicas para fortalecimento das políticas de conservação de Áreas de Reserva Legal no âmbito do Cerrado, bioma prioritário para conservação da biodiversidade, melhorando a caracterização dos recursos medicinais ainda disponíveis na flora nativa regional bem como vislumbrando suas aplicações biológicas e farmacológicas.
\end{abstract}

Palavras-chave: Fitoquímica, Prospecção, Plantas Medicinais, Cerrado, biodiversidade.

ABSTRACT: Preliminary phytochemical screening of native Cerrado plants of medicinal popular use by the rural community of the Vale Verde settlement - Tocantins. This qualitative study aimed to characterize the groups of secondary metabolites and some constituents of 9 species of native medicinal plants of the Cerrado region used by the rural community of Vale Verde Settlement, identifying their biological and pharmacological potential. The information on medicinal plants were obtained through ethnobotanical and ethnopharmacological studies performed during the period 2010-2012. The botanical material collected was identified and deposited in the Herbarium of the Federal University of Tocantins, Porto Nacional (TO). The ethanolic and methanolic extracts were obtained from the oven dried material, filtered and concentrated in a rotary evaporator under reduced pressure, then weighed and placed again in an oven for $24 \mathrm{~h}$ at $50^{\circ} \mathrm{C}$, obtaining the yield $(\mathrm{m} / \mathrm{m})$, resulting from the ratio between the mass of concentrated extract and the mass after drying. Phytochemical analysis of selected

Recebido para publicação em 23/12/2011

Aceito para publicação em 28/08/2013

Rev. Bras. PI. Med., Campinas, v.15, n.4, supl.I, p.692-707, 2013. 
plants was done using the methodology of Preliminary Prospecting, with tests for the detection of some important constituents and of the main groups of metabolites: saponins, phenols and tannins, catechins, steroids and triterpenoids, coumarins, anthraquinones and flavonoids. The tests were considered positive by the reactions of precipitates with colorations, the formation of foams and colored stains. Phytochemical tests performed on the extracts revealed the presence of constituents of secondary metabolism of plants, which can help to identify chemical markers of species. These markers are indispensable for testing quality and integrity of phytochemicals and a safer popular use of medicinal plants, enabling a better pharmacognostic control of these species and guidance for their use and applications in research by the preliminarily known bioactivity. In this case, it is especially due to the antimicrobial, antioxidant and anti insect activities, suggesting an association with the presence of phenolic compounds and flavonoids, positive in extracts of most species. These data are novel in Tocantins and strategic for the strengthening of conservation policies of Legal Reserve Areas within the Cerrado, priority biome for the conservation of biodiversity, improving the characterization of medicinal resources still available in the regional native flora, also foreseeing their biological and pharmacological applications.

Keywords: Phytochemistry, Prospecting, Medicinal Plants, Cerrado, biodiversity.

\section{INTRODUÇÃO}

O uso de plantas medicinais tem relevância sócioeconômica muito grande na qualidade de vida das comunidades de baixa renda, devido a sua alta disponibilidade, baixa toxicidade, risco mínimo de efeitos colaterais e principalmente aos baixos custos e/ou sem ônus comparados aos medicamentos alopáticos (Rodrigues \& Carvalho, 2001). Esta é uma realidade muito comum no meio rural brasileiro, associada também às dificuldades de acesso aos serviços básicos de saúde pública. $O$ processo de levantamento, resgate de informações e identificação de espécies medicinais nativas do Cerrado é importante mediante o potencial econômico e medicinal dessas plantas provenientes deste bioma (Silva et al., 2010), ainda pouco conhecido e com disponibilidade futura comprometida devido à ameaça como desmatamento e queimadas, ameaçando inclusive Áreas de Reserva Legal, o que tem levado a perda da biodiversidade medicinal.

Entretanto, as pesquisas ainda são poucas e existem lacunas referentes ao conhecimento cientifico de compostos bioativos produzidos pelas espécies desse bioma, repercutindo em uma realidade brasileira onde, embora se tenha a maior diversidade vegetal do mundo e muitas plantas medicinais sejam de amplo conhecimento popular, o número de informações sobre essas plantas tem crescido apenas 8\% anualmente (Guarin-Neto \& Morais, 2003; Silva et al., 2010; Corrêa \& Salgado, 2011).

A pesquisa fitoquímica é importante principalmente quando ainda não são dispostos todos os estudos químicos com espécies de interesse popular, tendo como objetivo conhecer os compostos químicos das espécies vegetais e avaliar sua presença nos mesmos, identificando grupos de metabólitos secundários relevantes (Simões et al., 2004) úteis enquanto marcadores químicos no monitoramento das plantas medicinais em processo de domesticação (Leite, 2009), na qualidade da matéria prima medicinal e na prospecção da biodiversidade ou bioprospecção (Braga, 2009). A etnobotânica aplicada ao estudo de plantas medicinais trabalha em estreita cumplicidade com a etnofarmacologia que consiste na exploração científica e interdisciplinar de agentes biologicamente ativos, que sejam tradicionalmente empregados ou observados por determinado agrupamento humano (López, 2006). Assim, estas áreas do conhecimento devem ser utilizadas em pesquisas de novas substâncias oriundas de plantas, tendo: a etnobotânica a incumbência de buscar informações a partir do conhecimento de diferentes povos e etnias; a fitoquímica o desempenho de identificação, purificação, isolamento e caracterização de princípios ativos; e a farmacologia o estudo dos efeitos farmacológicos de extratos e dos constituintes químicos isolados (Albuquerque \& Hanazaki, 2006). Esta atuação interdisciplinar é necessária e amplia as buscas direcionadas para o campo da bioatividade das plantas medicinais levando em conta também os aspectos agrotecnológicos, microbiológicos, farmacológicos e biotecnológicos (Foglio et al., 2006).

A orientação para tais estudos ocorre a partir dos usos indicados popularmente em medida que a detecção de atividade biológica nessas plantas é certamente mais seletiva do que em plantas escolhidas ao acaso (Yunes, 2001). As plantas utilizadas na medicina tradicional estão sendo também cada vez mais estudadas por serem possíveis fontes de substâncias com atividades antimicrobianas frente a microorganismos prejudiciais a saúde do homem (Mendes et al., 2011), a agricultura e a pecuária (Corrêa \& Salgado, 2011) contribuindo para suas aplicações no campo

Rev. Bras. PI. Med., Campinas, v.15, n.4, supl.I, p.692-707, 2013. 
da agroecologia.

No âmbito da saúde, a política pública vigente no Brasil recomenda a promoção da popularização do uso de plantas medicinais e fitoterapia na atenção primária, entretanto, com eficácia, segurança e práticas de conservação da biodiversidade medicinal. Um dos fatores que contribui com esta questão no País é a geração de conhecimento sobre os princípios ativos da matéria prima nos vários biomas e seus respectivos ecossistemas, principalmente devido à grande extensão territorial e plantas obtidas de várias localidades, levando as dificuldades relacionadas ao controle de qualidade dessas opções terapêuticas (Vilegas et al., 2009). A triagem fitoquímica é um procedimento importante para bioprospecção das espécies vegetais de interesse farmacológico e/ou toxicológico. A composição química de um extrato pode ser conhecida através de testes químicos qualitativos rápidos e de baixo custo, sugerindo as possíveis classes de metabólitos secundários de interesse (Mattos, 1997).

Diante deste contexto realizou-se o estudo fitoquímico preliminar com os extratos de folhas de plantas medicinais do Cerrado de uso popular verificado a partir do levantamento etnobotânico e etnofarmacológico, realizados junto a comunidade rural do Assentamento rural Vale Verde, região sul do Estado do Tocantins. A abordagem fitoquímica de extratos etanólico e metanólico de 9 espécies nativas medicinais do Cerrado foi priorizada na perspectiva de identificar os grupos de metabólitos secundários e alguns constituintes, como catequinas presentes, vislumbrando resultados indicativos para possíveis marcadores químicos. Trata-se de uma contribuição para qualidade da matéria prima visando aplicações biológicas na agroecologia e na saúde, com condutas terapêuticas mais seguras relacionadas às plantas medicinais e aos fitoterápicos. A indicação popular relatada no levantamento etnobotânico e etnofarmacológico orientou a busca pelas atividades biológicas das espécies e constituintes fitoquímicos relacionados de forma a justificar a adequação ou não do uso medicinal popular e futuros estudos de bioprospecção envolvendo espécies de plantas medicinais promissoras e nativas do Cerrado, bioma prioritário para conservação da biodiversidade.

\section{MATERIAL E MÉTODO}

\section{estudo}

Localização e caracterização da área de

O Assentamento Vale Verde foi criado no dia 16 de abril de 2003, pela Portaria INCRA/SR-26/ $N^{\circ} 09 / 2003$. Está localizado entre as coordenadas S $11^{\circ} 52.582 \mathrm{~W} 048^{\circ} 58.913$ (Figura 1) e situado a 15 km do perímetro urbano de Gurupi, no sul do Estado do Tocantins. Possui uma área total de 1765,18 hectares, tendo sido dimensionado para atender 100 famílias, com área média de 10 hectares por lote onde praticam agricultura e pecuária de subsistência como principal atividade produtiva. A área restante (35\% do total) foi demarcada e preservada como Área de Reserva Legal comunitária (INCRA/ RURALTINS, 2004).

\section{Levantamento Etnobotânico e Etnofarma- cólogico}

Este levantamento foi realizado de janeiro a dezembro de 2010 por meio de uma entrevista individual aplicada junto a um representante

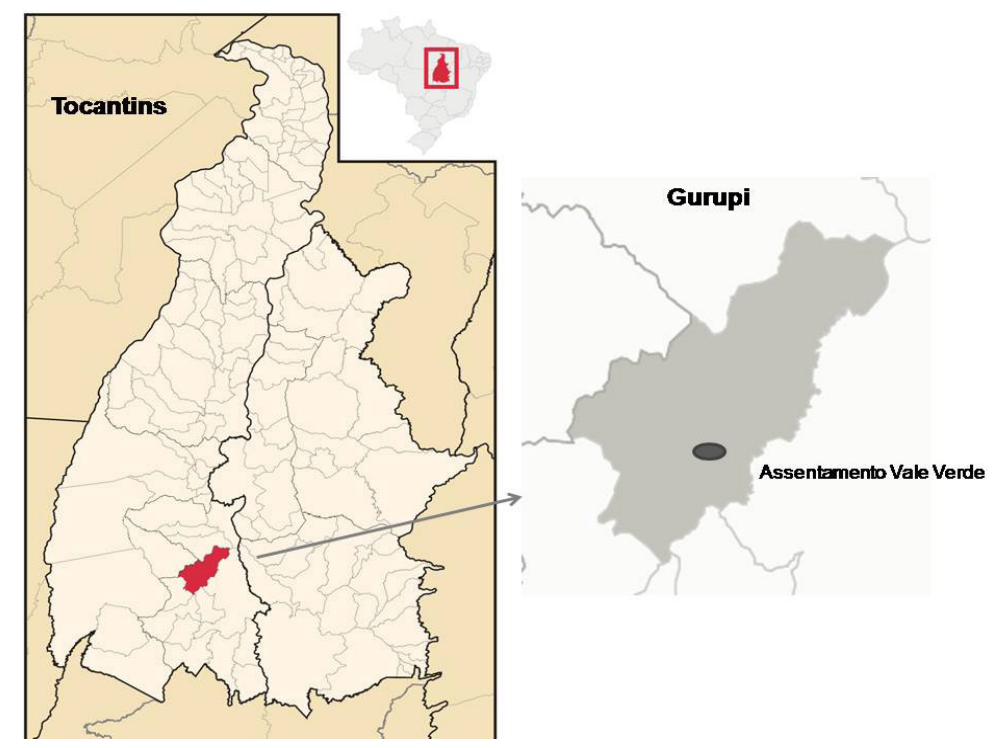

FIGURA 1. Localização geográfica do Assentamento rural Vale Verde, Município de Gurupi, Estado do Tocantins, 2012. 
adulto de cada uma das cem (100) famílias do assentamento, preferencialmente de mais idade devido ao conhecimento acumulado. Foi utilizado um questionário estruturado, contendo perguntas abertas e fechadas, abordando sobre o perfil sóciodemográfico, etnobotânica (origem do conhecimento, plantas utilizadas, classificação em nativas ou exóticas, usos e indicações populares, incluindo usos produtivos alternativos) e etnofarmacologia (doenças mais frequentes e respectivas condutas terapêuticas adotadas pela comunidade).

\section{Material Botânico}

As 9 espécies estudadas foram selecionadas por serem plantas medicinais nativas do bioma Cerrado, presentes no Assentamento Vale Verde e cujos usos e indicações foram mais citadas no levantamento etnobotânico e etnofarmacológico.

As folhas e flores das espécies medicinais nativas do Cerrado foram coletadas no Assentamento no período de janeiro a dezembro de 2010 de acordo com a época de floração e frutificação de cada espécie. As exsicatas das 9 espécies foram identificadas pelo Prof. DSc. Rodney Viana e depositadas no herbário da Universidade Federal de Tocantis - UFT (campus de Porto Nacional - TO), sendo: Anacardium othonianum Rizz. (S 1152.814 W 048 59.009; registro 10297); Brosimum gaudichaudii Trécul. (S 11052.850 W 048 59.140; registro 10293); Cecropia pachystachya T.(S 11052.817 W 04858.991; registro 10.068); Hymenaeae courbaril L.(S 11'52.807 W 04859.142, registro 10289); Jenipa americana L.(S 11052.807 W 048 59.142; registro 10295); Myracrodruon urundeuva Fr. All.(S 11052.786 W 4858.946; registro 10290); Siparuna guianensis Aublet.

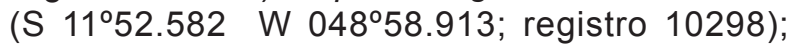
Stryphnodendron obovatum Benth.(S 11 ${ }^{\circ} 52.550 \mathrm{~W}$ 04858.142; registro 10296); Vernonia brasiliana (L.) Druce (S $11^{\circ} 52.853$ W 048 59.014 ; registro 10292).

\section{Obtenção do Extrato}

As folhas das 9 espécies estudadas foram coletadas e submetidas a secagem em estufa à temperatura de $40^{\circ} \mathrm{C}( \pm 0,5)$ por 3 dias e trituradas em moinho de facas tipo Willey (EDB-5). Os extratos foram preparados a partir da pesagem de $100 \mathrm{~g}$ do pó das folhas de cada espécie. Em seguida fez-se a extração por maceração em $500 \mathrm{ml}$ de solução etanólica (álcool etílico marca Dinâmica) a $95 \%$ durante 7 dias, sendo C. pachystachya extraído com solução metanólica (álcool metílico, marca Dinâmica) a 95\%. Os filtrados etanólico e metanólico foram concentrados em evaporador rotatório sob pressão reduzida (temperatura de até $50^{\circ} \mathrm{C}$ ) e em seguida pesados. Os concentrados foram secos em estufa por $24 \mathrm{~h}$ a $50^{\circ} \mathrm{C}$ e novamente pesados. Calculou-se o rendimento (\%) do extrato concentrado e após secagem, através da relação entre as massas $(\mathrm{g})$ do extrato concentrado $(\mathrm{m})$ e após sua secagem $(\mathrm{m})$.

\section{Fitoquímica e Prospecção dos Constituintes da Planta}

Os extratos etanólico (8) e metanólico (1) foram submetidos a uma série de reações de caracterização fitoquímica: açúcares redutores (reação de Benedict: Fehling $A$ usando como reagente o sulfato cúprico/marca Synth e B usando hidróxido de sódio/marca Dinâmica e tartarato de sódio e potássio/marca F. Maia); saponinas (teste de espuma-agitação); fenóis e taninos (reação com cloreto férrico/marca Dinâmica); esteróides e triterpenos (extração com clorofórmio/marca Dinâmica, anidrido acético/marca Vetec e ácido sulfúrico/marca F. Maia), cumarinas (extração com éter etílico/marca Dinâmica e observação sob a luz ultravioleta), alcalóides (Reativos de Dragendorff usando carbonato de bismuto/marca Vetec e iodeto de potássio/marca Caal nacional), catequinas (reação com ácido clorídrico/marca Dinâmica e aquecimento), flavonóides (reação com magnésio granulado/marca Vetec com ácido clorídrico/marca Dinâmica), antraquinonas (reação com tolueno/ marca F. Maia e hidróxido de amônio/marca Synth). A metodologia utilizada seguiu Mattos (1997), Simões et al. (2004) e Miranda et al. (2013). A presença ou ausência dos grupos de metabólitos secundários e de alguns constituintes das 9 espécies estudadas foi verificada a partir da observação da reação característica esperada ou não, indicando a presença de resultado positivo ou negativo para cada grupo e constituinte analisado (Mattos, 1997), (Tabela 2).

\section{RESULTADO E DISCUSSÃO}

\section{Levantamento Etnobotânico e Etnofarma- cológico}

O conhecimento popular sobre as plantas medicinais bem como as condutas terapêuticas utilizadas pela comunidade rural do Assentamento Vale Verde, município de Gurupi-TO, foi constatado por meio do levantamento etnobotânico e etnofarmacológico, realizado junto $81 \%$ das famílias. Foram citadas 104 plantas com finalidades terapêuticas, destas $43,7 \%$ são nativas e $55,3 \%$ são exóticas (Figura 1), evidenciando o valor local dado a flora medicinal do Cerrado (Guarin-Neto \& Morais, 2003) e o potencial medicinal a ser pesquisado (Silva et al., 2010).

O uso de plantas medicinais é a conduta 


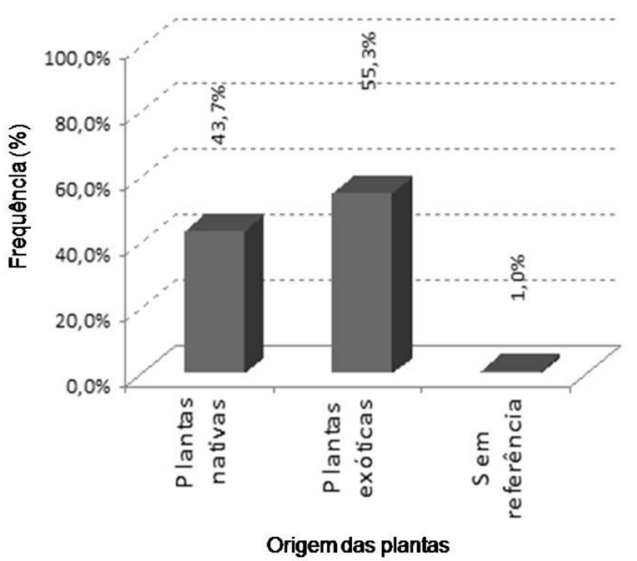

FIGURA 1. Frequência (\%) de plantas medicinais nativas e exóticas usadas pela comunidade rural Vale Verde. Gurupi -TO, 2012.

terapêutica prioritária $(46,5 \%)$ da comunidade (Figura 2), cuja origem do conhecimento (98\%) advém da rede familiar e de outras pessoas do assentamento. A renda mensal é de até um salário mínimo (45\%). Neste tipo de cenário é comum o uso de plantas medicinais, devido à disponibilidade sem ônus desse importante recurso terapêutico (Rodrigues \& Carvalho, 2001).

As espécies medicinais estudadas foram agrupadas (Tabela 1) seguindo a identificação botânica, a denominação conhecida pela comunidade rural bem como as substâncias bioativas indicadas na literatura e o contraste entre a indicação popular local e as atividades biológicas que constam também na literatura. Verificou-se que o conhecimento empírico da comunidade apontou para 52 diferentes indicações terapêuticas para as 9 espécies medicinais estudadas não havendo correspondência, em alguns casos, entre indicação empírica em relação a atividade biológica relatada na literatura (Tabela 1). Isto ocorreu em relação, por

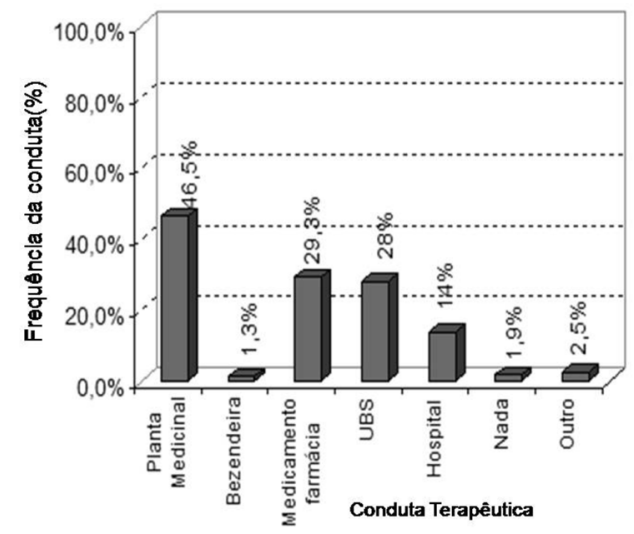

FIGURA 2. Plantas medicinais como conduta terapêutica prioritária (freqüência) pela comunidade rural Vale Verde. Gurupi -TO, 2012. exemplo, a Hymenaeae Coubaril L. (jatobá) com indicação popular local para uso de chá das folhas como controle da anemia e de problemas no fígado, não havendo indicação destes usos na literatura assim como para Stryphnodendron Obovatum Benth. (barbatimão), onde a população faz uso como antibiótico natural. Mas neste caso, é possível essa generalização por parte da comunidade mediante sua ampla atividade biológica citada na literatura. Dentre as possíveis explicações para estes fatos temse a presença ou ausência de determinado grupo de metabolitos secundários e outros constituintes específicos nas plantas das espécies estudadas, o que sinalizaria preliminarmente para a necessidade de um possível marcador químico (Emerenciano et al., 2005), ajudando na melhor conduta terapêutica e não adulteração de matéria prima e aplicações mais seguras.

Várias plantas medicinais foram relatadas pela comunidade com seus usos respectivos e freqüência de citação: problemas respiratórios gripes, resfriados (34\%) com uso do assa-peixe (Vernonia brasiliana), folha santa ou negramina (Siparuna guianensis), Cajuí (Anacardium othonianum), alfavaca (Ocimum $\mathrm{sp}$ ), fedegoso (Stachytarpheta sp), malva do reino (Gossypium sp), manjericão (Ocimum sp), melão de São Caetano (Momordica sp), poejo (Mentha sp), sete dores (Plectranthus sp) e sucupira (Pterodon sp); com relatos de uso para hipertensão (22\%) a amora (Morus sp) e o capim santo (Lippia sp); usando o inharé (Brosimum gaudichaudii), a batata de purga (Operculina sp), a erva de santa Maria (Chenopodium sp) e a terramicina (Pfaffia sp) para verminoses $(11 \%)$; dores na coluna usando a negramina (Siparuna guianensis), dores nos rins usando a embaúba (Cecropia pachystachya) e problemas cardíacos com uso de baru (Dipteryx sp) resultaram em $8 \%$ dos relatos; diabete ( $8 \%$ ) com uso de cajuí (Anacardium othonianum), jenipapo (Genipa americana), coquinho-do-cerrado (Syagrus sp), picão (Bidens sp), pereira (Aspidosperma sp) e quinado-cerrado (Strychnos sp); infecções (7\%) com uso da negramina (Siparuna guianensis), barbatimão (Stryphnodendron obovatum), cajuí (Anacardium othonianum), aroeira (Myracrodruom sp), folha grossa (Kalanchoe sp), gervão (Stachytarpheta sp), jatobá (Hymenaea sp), mangabeira (Hancornia sp), sete dores (Plectranthus sp) e sucupira (Pterodon $\mathrm{sp})$; dores de cabeça (5\%) com uso de negramina (Siparuna guianensis), lima de bico (Citrus sp) e vick (Jatropha sp); câncer (3\%) com uso de assa-peixe (Vernonia brasiliana); úlcera (2\%) com uso de assa-peixe (Vernonia brasiliana), inharé (Brosimum gaudichaudii), açoita cavalo (Leuhea $\mathrm{sp}$ ) e espinheira (Maytenus sp). As enfermidades ocorrem, segundo os relatos, mais em pessoas

Rev. Bras. PI. Med., Campinas, v.15, n.4, supl.I, p.692-707, 2013. 
do sexo masculino $(66,9 \%)$ que do sexo feminino $(33,1 \%)$, sendo os adultos mais acometidos $(38,8 \%)$, idosos $(33,6 \%)$ seguido de crianças $(25,5 \%)$ e de jovens $(2,1 \%)$.

Fitoquímica, Prospecção dos Constituintes e Atividade Biológica

Os extratos etanólicos do cajuí - Anacardium othonianum Rizz. (1), inharé - Brosimum gaudichaudii Trécul. (2), jatobá - Hymenaeae courbaril L. (4), jenipapo - Genipa americana L. (5), aroeira Myracrodruon urundeuva Fr. All. (6), negramina -Siparuna guianensis Aublet. (7), barbatimão Stryphnodendron obovatum Benth. (8), assa peixe - Vernonia brasiliana (L.) Druce (9) e o extrato metanólico de embaúba - Cecropia pachystachya T.(3) indicaram presença de diferentes grupos de metabólitos secundários e alguns constituintes, sugerindo biodisponibilidade de saponinas, fenois, taninos, esteróides, triterpenos e flavonoides na

TABELA 1. Identificação de 09 espécies medicinais nativas do Cerrado e de uso popular local, substâncias bioativas, indicação popular e atividades biológicas indicadas na literatura.

\begin{tabular}{|c|c|c|c|c|c|}
\hline Família & Espécie & $\begin{array}{c}\text { Nome } \\
\text { popular local }\end{array}$ & Substâncias bioativas & $\begin{array}{l}\text { Indicação da } \\
\text { população } \\
\text { local }\end{array}$ & Atividades biológicas \\
\hline Anacardiaceae & $\begin{array}{c}\text { Anacardium } \\
\text { othonianum Rizz. }\end{array}$ & $\begin{array}{l}\text { Cajuzinho-do- } \\
\text { cerrado ou } \\
\text { Cajuí }\end{array}$ & $\begin{array}{l}\text { Compostos fenólicos, } \\
\text { catecólicos, taninos } \\
\text { condensados e } \\
\text { alcalóides } \\
\text { (Silva et al., 2007; } \\
\text { Rocha et al., 2011; Trox } \\
\text { et al., 2011) }\end{array}$ & $\begin{array}{l}\text { Inflamações, } \\
\text { patologias } \\
\text { respiratórias } \\
\text { (tosse, gripe), } \\
\text { diabetes, dores }\end{array}$ & $\begin{array}{c}\text { Gastrite, larvicida, } \\
\text { antimicrobiana, antioxidante, } \\
\text { hipoglicemiante, adstringente, } \\
\text { tônico, antiinflamatória } \\
\text { (Oliveira \& Saito, 1989; Olajide } \\
\text { et al., 2004; Barbosa-Filho et } \\
\text { al., 2005; Mendonça et al., } \\
\text { 2005; Morais et al., 2005; Silva } \\
\text { et al., 2007; Kamath \& Rajini, } \\
\text { 2007; Porto et al., 2008) }\end{array}$ \\
\hline Moraceae & $\begin{array}{l}\text { Brosimum } \\
\text { gaudichaudii } \\
\text { Trécul. }\end{array}$ & Inharé & $\begin{array}{c}\text { Compostos fenólicos, } \\
\text { terpenóides } \\
\text { Furanocumarinas, } \\
\text { bergapteno e psoraleno } \\
\text { (Vilegas et al.,1993; } \\
\text { Varanda et al., 2002; } \\
\text { Jacomassi et al., 2007; } \\
\text { Rocha et al. , 2011) }\end{array}$ & $\begin{array}{l}\text { Inflamações, } \\
\text { depurativo, } \\
\text { úlcera, gastrite }\end{array}$ & $\begin{array}{c}\text { Antimicrobiana e atividade } \\
\text { fotossensibilizante (Silva et al., } \\
\text { 2012; Pozetti, 2005; Leão et al., } \\
\text { 2005) }\end{array}$ \\
\hline Cecropiaceae & $\begin{array}{c}\text { Cecropia } \\
\text { pachystachya T. }\end{array}$ & Embaúba & $\begin{array}{l}\text { Alcalóides, flavonóides, } \\
\text { triterpenos e esteróides, } \\
\text { catequinas } \\
\text { (Tanae et al., 2007; } \\
\text { Costa et al., 2011) }\end{array}$ & $\begin{array}{l}\text { Analgésico (Dor } \\
\text { nos rins) }\end{array}$ & $\begin{array}{l}\text { Expectorante, antitussígeno, } \\
\text { antiasmático e hipoglicemiante, } \\
\text { anti-hipertensiva (Lorenzi } \\
\text { \& Matos 2002; Consolini \& } \\
\text { Migliori, 2005) }\end{array}$ \\
\hline Caesalpinaceae & $\frac{\text { Hymenaeae }}{\text { courbaril L. }}$ & Jatobá & $\begin{array}{c}\text { Diterpenos, óleos } \\
\text { essenciais, taninos, } \\
\text { substâncias amargas, } \\
\text { matérias resinosas } \\
\text { e pécticas, amido e } \\
\text { açúcares, xiloglucanas, } \\
\text { galactomananas, } \\
\text { oligossacarídeos e } \\
\text { ácidos graxos } \\
\text { (Panizza, 1997; } \\
\text { Nogueira et al., 2001) }\end{array}$ & $\begin{array}{l}\text { Dores, gastrite, } \\
\quad \text { infecção, } \\
\text { anemia, fígado, } \\
\text { dor nos nervos; } \\
\text { inflamação }\end{array}$ & $\begin{array}{l}\text { Anti-séptico, antiinflamatória } \\
\text { (Teixeira \& Melo, 2006; } \\
\text { Jayaprakasam et al., 2007) }\end{array}$ \\
\hline
\end{tabular}


TABELA 1. Identificação de 09 espécies medicinais nativas do Cerrado e de uso popular local, substâncias bioativas, indicação popular e atividades biológicas indicadas na literatura.

...continuação

\begin{tabular}{|c|c|c|c|c|c|}
\hline Família & Espécie & $\begin{array}{c}\text { Nome } \\
\text { popular local }\end{array}$ & Substâncias bioativas & $\begin{array}{c}\text { Indicação da } \\
\text { população } \\
\text { local }\end{array}$ & Atividades biológicas \\
\hline Rubiaceae & $\begin{array}{c}\text { Genipa } \\
\text { americana L. }\end{array}$ & Jenipapo & $\begin{array}{l}\text { Compostos terpênicos: } \\
\text { genipacetal, genipamida } \\
\text { e genipaol; manitol, } \\
\text { taninos, metil-éteres, } \\
\text { hidantoína, ácidos } \\
\text { tânicos, iridoides, } \\
\text { antraquinonas e } \\
\text { alcalóides. } \\
\text { (Revilla, 2001; } \\
\text { Cronquist, 1981; Ono et } \\
\text { al.,2007; Souza et al., } \\
\text { 2013) }\end{array}$ & Diabetes & $\begin{array}{c}\text { Repelente de insetos, } \\
\text { gonorréia, adstringente, } \\
\text { antiinflamatórias e } \\
\text { antianêmicas, propriedades } \\
\text { tônicas e febrífugas, } \\
\text { enfermidades oftálmicas, } \\
\text { purgativo, feridas escorbúticas, } \\
\text { úlceras venéreas e faringites } \\
\text { granulosas, antissifílica o e } \\
\text { antidiarreico. (Corrêa, 1984; } \\
\text { Delprete et al., 2005; Vieira, } \\
\text { 2006; Souza et al., 2013) }\end{array}$ \\
\hline Anacardiaceae & $\begin{array}{c}\text { Myracrodruon } \\
\text { urundeuva Fr. All. }\end{array}$ & Aroeira & $\begin{array}{l}\text { Chalconas diméricas } \\
\text { saponinas, taninos e } \\
\text { esteróides, catequinas, } \\
\text { triterpenos, alcalóides e } \\
\text { flavonóides } \\
\text { (Viana et al., 1997; } \\
\text { Viana et al., 2003; } \\
\text { Dantas, 2003). }\end{array}$ & $\begin{array}{l}\text { Inflamações, } \\
\text { garganta } \\
\text { infecção de rins, } \\
\text { cicatrizante, } \\
\text { gastrite, } \\
\text { diarréia, } \\
\text { impurezas do } \\
\text { sangue }\end{array}$ & $\begin{array}{l}\text { Antiinflamatório, cicatrizante, } \\
\text { antimicrobiana, inflamações } \\
\text { e infecções genito-urinário, } \\
\text { pele e sistema digestivo, } \\
\text { Inflamações em geral (útero e } \\
\text { ovários, gastrite, úlcera). (Viana } \\
\text { et al., 1995; Viana et al., 2003; } \\
\text { Monteiro et al., 2006; Oliveira et } \\
\text { al., 2010; Pinho et al., 2012) }\end{array}$ \\
\hline Siparunaceae & $\begin{array}{c}\text { Siparuna } \\
\text { guianensis Aublet }\end{array}$ & Negramina & $\begin{array}{l}\text { Saponinas, taninos, } \\
\text { catequinas, esteróides, } \\
\text { triterpenos, depsídeos, } \\
\text { depsinonas, azuleno, } \\
\text { cumarinas, alcalóides e } \\
\text { flavonóides, compostos } \\
\text { não terpênicos. } \\
\text { Metilcetonas, ácidos } \\
\text { graxos, éteres, ésteres, } \\
\text { compostos fenólicos, } \\
\text { óleos essenciais e } \\
\text { lignanas } \\
\text { (Fischer, 1999; Fischer, } \\
\text { 1997; Fischer, 2005; } \\
\text { Valentini et al., 2010a; } \\
\text { Valentini et al., 2010b) }\end{array}$ & $\begin{array}{c}\text { Febre, } \\
\text { antiinflamatória, } \\
\text { gripes e } \\
\text { resfriados, } \\
\text { bronquites, } \\
\text { reumatismo, } \\
\text { dores de } \\
\text { cabeça, dores } \\
\text { na coluna, } \\
\text { contra piolho de } \\
\text { galinha }\end{array}$ & $\begin{array}{l}\text { Febre, hipertensão, doenças } \\
\text { reumáticas e cólicas, dores na } \\
\text { coluna, reumatismo e artrite, } \\
\text { mordedura de serpentes, } \\
\text { Inalação para dor de cabeça, } \\
\text { poderes sobrenaturais, usadas } \\
\text { para descarrego, analgésico, } \\
\text { excitante, carminativo e } \\
\text { contusões, vermes de animais } \\
\text { domésticos, Dores musculares } \\
\text { (Fischer, 1997; Souza \& Felfili, } \\
\text { 2006; Arjona et al. 2007; Alves } \\
\text { et al. 2008; Coelho \& Santos } \\
\text { 2008; Valentini et al., 2010b) }\end{array}$ \\
\hline Mimosaceae & $\begin{array}{l}\text { Stryphnodendron } \\
\text { obovatum Benth. }\end{array}$ & Barbatimão & $\begin{array}{l}\text { Inibidores de proteases, } \\
\text { taninos, saponinas, } \\
\text { inibidores de tripsina, } \\
\text { alcalóides, terpenos, } \\
\text { esteróides, estilbenos e } \\
\text { flavonóides } \\
\text { (Oliveira et al., 2002; } \\
\text { Soares et al., 2002a; } \\
\text { Pinho et al., 2012). }\end{array}$ & $\begin{array}{c}\text { Cicatrizante, } \\
\text { antibiótico } \\
\text { natural }\end{array}$ & $\begin{array}{c}\text { Antidiarréico e úlcera } \\
\text { gástrica, atividade enzimática, } \\
\text { cicatrizante, antioxidante e } \\
\text { antifúngica (Vasconcelos 2004; } \\
\text { Sanches et al., 2005) }\end{array}$ \\
\hline
\end{tabular}

continua...

Rev. Bras. PI. Med., Campinas, v.15, n.4, supl.I, p.692-707, 2013. 
TABELA 1. Identificação de 09 espécies medicinais nativas do Cerrado e de uso popular local, substâncias bioativas, indicação popular e atividades biológicas indicadas na literatura.

...continuação

\begin{tabular}{|c|c|c|c|c|}
\hline Asteraceae & $\begin{array}{c}\text { Vernonia } \\
\text { brasiliana (L.) } \\
\text { Druce }\end{array}$ & Assa-peixe & $\begin{array}{l}\text { Triterpenos, esteróides, } \\
\text { sesquiterpenos e } \\
\text { flavonóides (Filizola, } \\
\text { 2003; Emerenciano et } \\
\text { al., 2005; Maia et al., }\end{array}$ & $\begin{array}{l}\text { Bronquite, } \\
\text { gripe, } \\
\text { pneumonia, } \\
\text { tosse, câncer, } \\
\text { úlcera }\end{array}$ \\
\hline
\end{tabular}
2010)

\author{
Anticâncer, antinflamatória, \\ antifúngica e antibactericida, \\ Inibe atividade hemorrágica \\ causada por veneno \\ de serpente, laxativo, \\ antitrombótica, abortiva, \\ patologias respiratórias \\ (Frutuoso, 1994; Andrade et al., \\ 2000; Formisano et al., 2006; \\ Maia et al., 2010)
}

maioria das espécies (Tabela 2).

As amostras dos extratos etanólicos apresentaram os seguintes rendimentos $(\mathrm{m} / \mathrm{m})$ para as respectivas espécies estudadas: $A$. othonianum (11,5\%), B. gaudichaudii (7,6\%), H. courbaril $(4,2 \%)$, G. americana $(7,4 \%), M$. urundeuva $(12,4 \%)$, S. guianensis $(9,6 \%), S$. obovatum $(3,6 \%), V$. brasiliana $(6,2 \%)$. Para o o extrato metanólico de C. pachystachya o rendimento foi de $8,2 \%$.

Aconstatação das reações de caracterização fitoquímica dos extratos etanólicos e metanólico (Tabela 2) ocorreu pelas seguintes respostas: saponinas pela formação de espuma persistente e abundante; fenóis e taninos pela mudança na coloração, com a cor azul nos extratos etanólico de $M$. urundeuva e $S$. obovatum e cor verde nos extratos etanolicos e metanólico das demais espécies, com formação de precipitado; catequinas, com o surgimento de cor vermelha; esteróides e triterpenos, por extração com clorofórmio, anidrido acético e ácido sulfúrico; cumarina pelo desenvolvimento de fluorescência azulada progressiva e forte na parte exposta da mancha; antraquinonas com precipitado de coloração vermelha; alcalóides, com aparecimento do precipitado laranja avermelhado para os reativos de Mayer e Bouchardat e do precipitado vermelho tijolo no Reativo de Dragendorff; e por fim flavonóides pelo aparecimento ou intensificação da cor vermelha no precipitado.

O resultado da prospecção fitoquímica preliminar dos grupos de metabólitos secundários e constituintes a partir dos extratos foliares de algumas espécies investigadas diferem daqueles descritos na literatura para flavonóides, positivo em A. othonianum assim como cumarina e antraquinona

TABELA 2. Triagem fitoquímica preliminar de extratos foliares de 9 espécies de plantas medicinais nativas do Cerrado e de uso popular pela comunidade do Assentamento Rural Vale Verde, Tocantins.

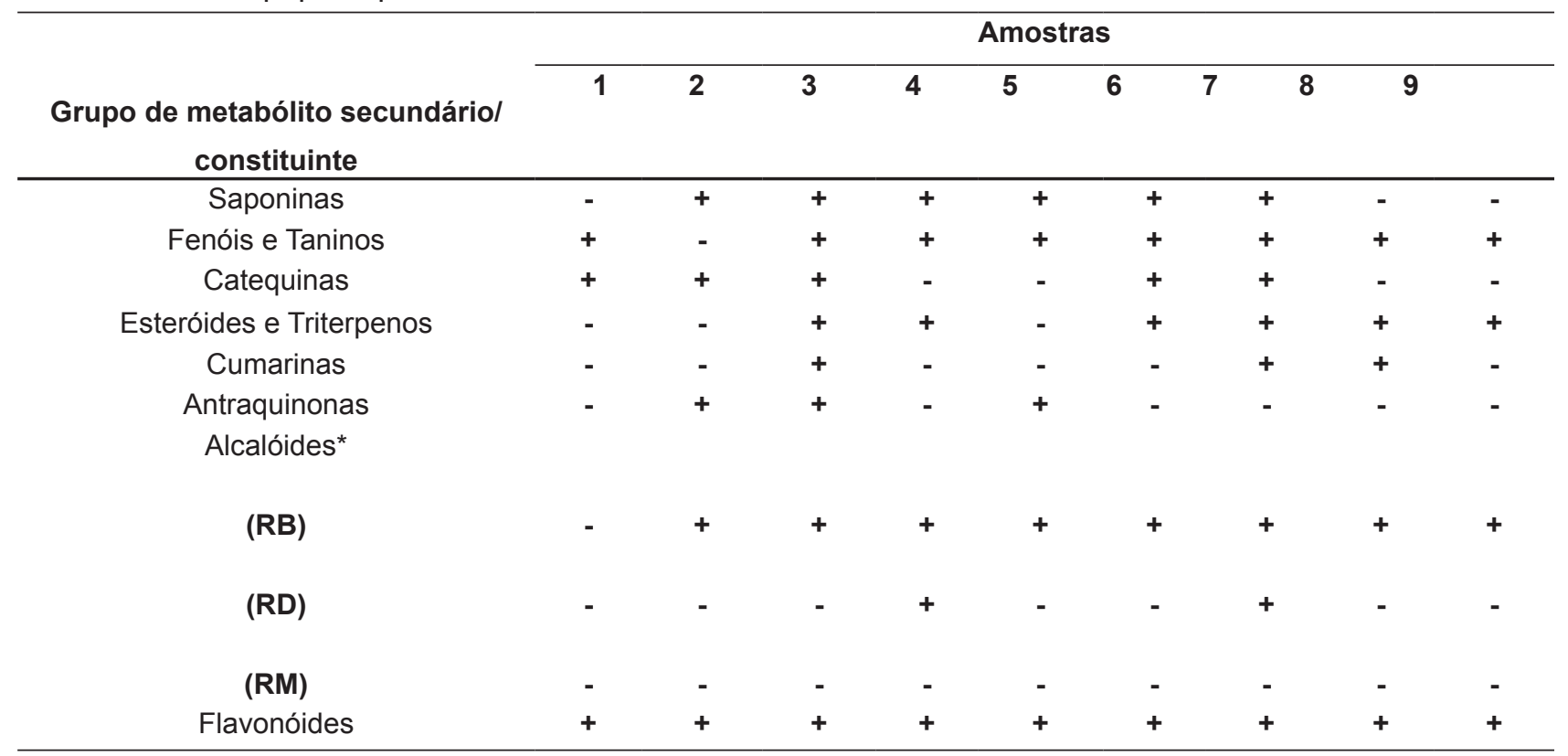

*Reativos Mayer (RM), Bouchardat (RB) e Dragendorff (RD); (+) Resultado positivo; (-) Resultado negativo

Rev. Bras. Pl. Med., Campinas, v.15, n.4, supl.I, p.692-707, 2013. 
positivo para C. pachystachya, sem relatos na literatura consultada para as mesmas espécies, porém, para muitas espécies o resultado foi similar (Tabelas 1 e 2). Isto mostra que os fitoconstituintes do metabolismo secundário podem, para a mesma espécie, apresentar variações a partir das diferenças ambientais inerentes ao ecossistema (Matos, 1997; Leite, 2009). Esta questão assume relevância mediante necessidades de padronização das matérias primas vegetais medicinais visando a validação das plantas medicinais usadas localmente, o controle de fitoterápicos existentes e a qualidade assegurada para os novos, além do suporte para pesquisas envolvendo potenciais atividades biológicas. Conhecendo grupos de metabólitos secundários da flora medicinal em questão, mesmo que pela sua qualificação preliminar, tem-se no marcador químico um importante parâmetro de controle, o que não desconsidera a importância de estabelecer perfis de referência por meio da quantificação desses marcadores nas distintas localidades geográficas do nosso imenso território. Entretanto, discrepâncias de resultados ocorrem em comparações qualitativas e até mesmo quantitativas dos metabólitos secundários e isto se deve a aspectos relacionados ao solo, clima, coleta de material, temperatura e reagentes químicos utilizados (Silva et al., 2010).

De maneira geral, todas (9) as espécies sugerem potencialidade para atividade antimicrobiana devido aos constituintes fitoquímicos como saponinas, taninos, flavonóides, terpenóides e alcalóides (Okeke, 2001) e fenólicos, que podem estar associados com atividade antioxidante e antimicrobiana (Souza et al., 2013).

Entende-se que a aplicação dos métodos qualitativos, como a prospecção fitoquímica preliminar, é relevante por possibilitar screening inicial de mais baixo custo (Mattos, 1997) especialmente quando é ainda desconhecido o perfil fitoquímico de espécies medicinais potenciais pouco estudadas regionalmente e presentes em biomas de relevante interesse para conservação da biodiversidade.

Alguns constituintes químicos presentes nos extratos de plantas medicinais podem responder majoritariamente pela atividade biológica, embora sua forma de ação seja normalmente conjugada a determinada bioatividade. Portanto, é importante destacar suas principais propriedades biológicas e farmacológicas, sendo: saponinas, com atividade hemolítica, molusquicida, antiinflamatória, antifúngica, antibacteriana, antimicrobiana, antiparasitária, citotóxica e antitumoral, antiviral entre outras (Sparg et al., 2004); compostos fenólicos, apresentando capacidade antioxidante de neutralizar a atividade de radicais livres gerados no organismo, com associações a diversas doenças crônico-degenerativas como diabetes, câncer e processos inflamatórios inibindo também o risco das doenças cardiovasculares (Rocha et al., 2011); taninos, caracterizados como compostos fenólicos, apresentam atividade antioxidante e antinfecciosa, ação antibacteriana, antifungicida e antiprotozoária, na reparação de tecidos, regulação enzimática e protéica, estimulação das células fagocíticas e ação tumoral (Robbers et al., 1997), em processos de cura de feridas como pequenas ulcerações, queimaduras e inflamações (Mello \& Santos, 2001), em patologias estomacais (Haslam, 1989); catequinas pertencem a um grupo de polifenóis e apresentam uma série de atividades biológicas, antioxidantes, quimioprotetora, termogênicas, antiinflamatória e anticarcinogênica (Schmitz et al., 2005); esteróides, envolvidos no desenvolvimento e no controle do sistema reprodutor humano, funcionando como cardiotônicos, precursores de vitamina D, anticoncepcionais orais, agentes antiinflamatórios e agentes anabolizantes (Robbers et al., 1997); triterpenos, grupo mais importante de terpenóides, é reconhecido pelos efeitos antiinflamatórios, analgésicos, cardiovasculares e antitumorais (Ikeda et al., 2008); cumarinas, utilizadas no tratamento de doenças de pele, como psoríase, dermatoses, vitiligo e alguns compostos possuem efeito anticoagulante assim como os compostos antraquinônicos, usados devido a importante ação laxativa (Leite, 2009); alcalóides, bastante conhecido devido a atividades farmacológicas marcantes como a morfina e a tubocurarina, sendo princípio ativo de importante anestésico atual (Cunha \& Filho, 2009); os flavonóides, com atividade antioxidante, antiproliferativa e antiinflamatória (Muschietti \& Martino, 2009), antiulcerogenica e antimicrobiana (Pinto et al., 2000), antialérgica, hepatoprotetora, antitrômbica, antiviral e anticarcinogênica (Middleton Junior et al., 2000).

Os resultados da triagem fitoquímica realizada no extrato etanólico de $A$. othonianum (cajuzinho-do-cerrado ou cajuí) indicou presença de saponinas, fenóis e taninos (Tabela 2) sendo estas substâncias também encontradas em espécies da família Anacardiaceae (Sant'Anna-Santos et al., 2006; Rocha et al., 2011). O constituinte químico catequina, observada no extrato metanólico da castanha-de-caju, pode ser indicativo da presença de compostos fenólicos (Trox et al.; 2011) e assim sinaliza potencial para atividade antioxidante (Soares et al., 2002b; Kamath \& Rajini, 2007). Esta propriedade antioxidante atua no sistema biológico por meio da neutralização dos radicais livres gerados no organismo, o que justifica a indicação de ação contra o câncer e doenças cardiovasculares (Soares et al., 2002b). Chaves et al. (2010) sugerem que os extratos etanólicos, sobretudo o da casca do caule 
de $A$. occidentale poderá ser uma alternativa como aditivo em alimentos e preparações farmacêuticas e cosméticas em substituição aos antioxidantes sintéticos tóxicos devido à presença da catequina e epicatequina. O trabalho realizado por Silva et al. (2007) com o extrato hidroalcóolico da casca do caule da espécie $A$. occidentale apresentou atividade antimicrobiana devido a presença de taninos (compostos polifenólicos) e alcalóides. Esses estudos reforçam os resultados dessa triagem fitoquímica, exceto para alcalóides, ausente no extrato desta espécie (Tabela 1 e 2). Estas repostas são sugestivas de potencialidade no extrato para atividade hemolítica, antimicrobiana e antiinflamatória e assim apresentando correspondência tanto com a indicação de uso pela Comunidade rural Vale Verde quanto àquelas já preconizadas na literatura (Tabela 1).

Os resultados obtidos na triagem do extrato etanólico de $B$. gaudichaudii (inharé) sugerem a presença de saponinas, catequinas, antraquinonas, alcalóides e flavonóides (Tabela 2). Plantas que apresentam saponinas são citadas com determinadas ações farmacológicas, tais como antinflamatória, larvicida, hipocolesterolemiante, expectorante, ventrópica, moluscicida e cicatrizante (Lopes et al., 2011). A presença de compostos fenólicos na planta, sejam fenóis simples, ácidos fenólicos, cumarinas, flavonoides, estilbenos, taninos condensados e hidrolisáveis, lignanas e ligninas (Souza et al., 2007) sugerem que o extrato tem potencial atividade antinflamatória, justificando o uso popular dessa espécie, com comprovação na literatura (Tabela 1). A atividade antifúngica sobre leveduras do gênero Cândida, isoladas da mucosa vaginal, foi testada em concentração de $200 \mathrm{mg}$ de extrato bruto de $B$. gaudichaudii, com confirmação positiva do resultado (Silva et al., 2012). As cumarinas já foram isoladas a partir de extratos etanólicos dessa espécie, com identificação de constituintes específicos como o psoraleno e derivados apresentando ação contra micoses, urticária, psoríases, alopecia areata, herpes simples, parasitoses humanas e animais, além de outras dermatoses (Pozzeti, 2005). Existem poucas pesquisas relativas às demais espécies envolvidas neste estudo, voltados para abordagem fitoquímica e verificação da atividade biológica dos seus constituintes fitoquímicos.

No extrato metanólico das folhas de $C$. pachystachya (embaúba) observou-se resultados (Tabela 2) similares àqueles descritos na literatura quanto a presença dos fitoconstituintes do metabolismo secundário (Tabela 1). Assim, os alcalóides, flavonóides, triterpenos e esteróides, além das catequinas detectados neste estudo (Tabela 3), corroboram com os descritos com espécies do gênero Cecropia (Tanae et al., 2007). $\mathrm{Em}$ estudos voltados para quantificação de compostos fenólicos majoritários foi identificado que os flavonóides (ácido clorogênico, isoorientina, orientina e isovitexina) estão presentes no extrato metanólico foliar de C. pachystachya, sendo a isoorientina o constituinte específico principal e em maior quantidade, com indicação para marcador químico para a espécie (Costa et al., 2011). As indicações terapêuticas populares dessa espécie são para asma, pressão alta, inflamação e diurético, com bastante limitação de conhecimento por parte da comunidade rural do assentamento em questão, mencionando apenas a terapia para dores renais, em relação às suas demais finalidades e atividades biológicas já estudadas cientificamente (Tabela 1), o que requer mais ações de educação em saúde no campo visando a popularização do uso de plantas medicinais, porém, acompanhada de uma sensibilização quanto a segurança e eficácia. Em estudos anteriores há comprovação da ação hipotensiva e efeitos no sistema central nervoso, incluindo atividades ansiolíticas e antidepressivas, sugerindo alguma relação com flavonóides e catequinas como constituintes já confirmados na literatura para esta espécie.

O extrato etanólico de $H$. courbaril (jatobá) apresentou grupos de metabólitos secundários (Tabela 2) que, de maneira geral, sinalizam para atividades biológicas antinflamatórias (triterpenos), antimicrobianas (flavonóides; fenóis e taninos). A presença de esteróides e triterpenóides foi confirmada por outros autores como Nogueira et al. (2001) através do estudo com extrato de acetato de etila das cascas e da resina do tronco dessa espécie e detectaram a presença de diterpenos. Terpenóides, isolados dos frutos em estudos com a mesma espécie, apresentaram considerável atividade antinflamatória através da inibição das enzimas ciclooxigenases (Jayaprakasam et al., 2007). Gonçalves et al. (2005) verificaram que $H$. courbaril apresenta atividade antimicrobiana contra Proteus mirabilis e Staphylococcus aureus. Fernandes et al. (2005) descreveram que o extrato da entrecasca, o extrato hidroalcóolico, as soluções aquosas dos extratos e a seiva liofilizada de $H$. courbaril, apresentam atividade antimicrobiana contra Bacillus stearothermophylus, Escherichia coli, Micrococcus luteus, Staphylococcus aureus. Taninos apresentam um efeito adstringente no trato gastrointestinal, o que os torna úteis para o tratamento de diarréia e outras patologias estomacais (Haslam, 1989). As indicações farmacológicas mencionadas justificam o uso dessa planta medicinal para as finalidades terapêuticas indicadas pela comunidade rural do Vale Verde e algumas indicações da literatura (Figura 1). Entretanto, a indicação popular

Rev. Bras. PI. Med., Campinas, v.15, n.4, supl.I, p.692-707, 2013. 
local direciona o uso dessa espécie medicinal para anemia o que possivelmente esteja associado alguma ação dos esteróides, por ser precursor de vitamina D (Robbers et al.,1997) assim como usa as folhas dessa planta para tratamentos de problemas no fígado podendo esta indicação ter fundamentação a partir da contribuição da ação hepatoprotetora dos acalóides (Middleton Junior et al., 2000).

A triagem fitoquímica a partir do extrato etanólico da espécie G. americana (Jenipapo) indicou presença de taninos e fenóis, alcalóides, saponinas, esteróides e triterpenos (Tabela 3). Há registros na literatura em relação a três compostos terpênicos chamados de genipacetal, genipamida e genipaol (Ono et al., 2007) e substâncias químicas como manitol, taninos, metiléteres, hidantoína (Revilla, 2001). Os compostos orgânicos monoterpênicos, como iridoides, ocorrem exclusivamente na subclasse Asteridae, na qual a família Rubiaceae se encontra, apresentando diversas atividades farmacológicas, entre elas a antimicrobiana, a diurética, a laxativa e a citotóxica (Bruneton, 2001). Além dos iridóides, há a presença de antraquinonas e vários tipos de alcalóides, principalmente os indólicos (Cronquist, 1981), o que justifica o resultado positivo para alcalóides com a referida espécie. O uso dessa espécie a partir da folhas na forma de decocção para tratamento da diabete foi relatado por uma comunidade município de Cujubim, Rondônia (Santos \& Lima, 2009), indicação também citada pela comunidade do Assentamento Vale Verde (Figura 1), o que sugere estudos farmacológicos in vivo sejam realizados para validação ou não dessa indicação popular.

A espécie M. urundeuva (aroeira) mostrou por meio da prospecção do seu extrato etanólico a presença de alcalóides, fenóis e taninos (Tabela 2) que no Nordeste do Brasil, Estado do Ceará, é de uso popular a entrecasca desta planta da família Anacardiaceae justificando atividade antiinflamatória e cicatrizante para afecções ginecológicas e ferimentos cutâneos (Viana et al., 1995). Os fenóis possuem ação em processos inflamatórios (Rocha et al., 2011) e os taninos atuam em processos de cura de feridas, queimaduras e inflamações (Mello \& Santos, 2001). Isto justifica o uso popular dessa espécie com comprovação na literatura (Tabela 1). Estudos com os extratos dos brotos e renovos do caule dessa espécie permitiram comprovar a existência de taninos com ação analgésica e antinflamatória (Viana et al., 1997). Estes dados encontrados na literatura corroboram com os obtidos nesta pesquisa, sendo positivo para taninos. As catequinas e saponinas são outros constituintes que foram encontrados nesta espécie e que apresentam uma série de atividades biológicas, dentre elas, ambas tem atividade antiinflamatória (Sparg et al., 2004; Schmitz et al., 2005) e as saponinas tem, ainda, atividade antimicrobiana (Sparg et al., 2004), entre outras, mostrando que as indicações da comunidade para inflamações e gastrite estão de acordo com a literatura para a espécie e constituintes químicos. Em estudo com intuito de investigar o potencial fitoterápico de espécies da Mata Atlântica e Cerrado brasileiro observou por meio do rastreamento fitoquímico a presença de flavonóides, saponinas, taninos e taninos caquéticos, que possuem propriedades antimicrobianas (Pinho et al., 2012). As indicações populares e reveladas na literatura apresentam correspondência para a atividade biológica devido também a presença de saponinas e taninos, identificados na triagem em questão (Figuras 1 e 2).

O resultado da triagem fitoquímica (Figura 2) do extrato etanólico de $S$. guianensis (negramina) foi similar àqueles encontrados por Valentini et al. (2010a), sendo positivos para alcalóides e terpenos e por Fischer (1997) no que se refere aos alcalóides, fenóis, taninos e flavonóides, contudo, houve também positividade para cumarina. Este é um constituinte também muito importante para saúde humana devido a sua ação de anticoagulante. Os sesquiterpenos foram os constituintes químicos majoritários encontrados na composição volátil extraídas das folhas dessa espécie (Valentini et al., 2010a), explicando a potencialidade do óleo essencial (Porto, 2008) para controle de alguns insetos vetores de doenças, o que sugere ampliação dos estudos nesta linha de pesquisa usando extratos foliares frescos ou óleo essencial das plantas desta espécie. O resultado positivo verificado para presença de saponinas (Tabela 2) contraria os resultados de Fischer (1997), ao verificar negatividade para saponinas, embora tenha observado halo de espuma abundante não permanecendo após agitação imediata. Isto mostra que as reações empregadas na abordagem fitoquímica constituem um indicativo de presença dos componentes pesquisados e, algumas delas, podem não apresentar especificidade suficiente. A presença dos constituintes químicos referidos para esta espécie permite inferir que as indicações populares e a maioria das indicações encontradas na literatura (Tabela 1) sinalizam a atividade biológica correspondente as indicações da comunidade. Fischer et al. (2005) mencionam que óleos extraídos de amostras dessa espécie de duas regiões da Amazônia e uma do Panamá possuíam, como maior componente, os sesquiterpenos, enquanto que nas espécies do cerrado eram as metilcetonas e ácidos graxos, o que sinaliza para necessidades relacionadas também para identificação de quimíotipos por biomas brasileiros, 
possibilitando maior controle sobre a qualidade da matéria prima para fitoterápicos, como preconiza Vilegas et al. (2009).

Observou-se no extrato etanólico de $S$. obovatum (Barbatimão) positividade para saponinas, taninos e fenóis, esteróides e triterpenos, alcalóides e flavonóides (Tabela 2), confirmados na literatura com espécies vegetais da família Leguminosae. Os estudos já realizados demonstram a presença de inibidores de proteases, taninos, saponinas, inibidores de tripsina, alcalóides, terpenos, esteróides, estilbenos e flavonóides (Oliveira et al., 2002; Soares et al., 2002b). O potencial fitoterápico de barbatimão foi observado através do rastreamento fitoquímico para presença de esteróides, fenóis simples, flavonóides, saponinas e taninos, com verificação também de atividade antibacteriana de hidroalcoólicos de folhas frente a Staphylococcus aureus demonstrando atividade antimicrobiana utilizando as folhas da espécie (Pinho et al., 2012). Esta atividade foi confirmada também a partir de estudos fitoquímicos com cascas, raízes e sementes (Ardisson et al., 2002; Vasconcelos et al., 2004). As saponinas possuem atividade, antiinflamatória, antifúngica, antibacteriana, antimicrobiana, antiparasitária (Sparg et al., 2004), taninos tem ação antibacteriana, atividade antioxidante, ação fungicida, na reparação de tecidos, regulação enzimática em processos de cura de feridas (Mello \& Santos, 2001) e em patologias estomacais (Haslam, 1989), fenóis e flavonóides tem atividade antioxidante (Muschietti e Martino, 2009; Rocha et al., 2011). Isso justifica as indicações descritas na literatura para a espécie que são atividade enzimática, úlcera gástrica, cicatrizante, antioxidante e antifúngica, no entanto, apenas para o uso como cicatrizante está de acordo com o indicado na comunidade (Tabela 1).

A espécie $V$. brasiliana (assa-peixe) apresenta atividades biológicas antifúngica, antibacteriana (Oliveira et al., 2007; Bastos et al., 2008) decorrentes possivelmente da contribuição de triterpenos, já isolados também em extratos etanólicos desta espécie (Filizola, 2003). Sua ação antimutagênica (Nogueira, 2006) poderá ter associação com compostos fenólicos presentes, como os flavonóides, apresentando capacidade antioxidante e de neutralizar a atividade de radicais livres gerados no organismo, que estão associados a diversas doenças crônico-degenerativas (Rocha et al., 2011). Compostos bioativos como lactonas sesquiterpênicas com propriedades anticâncer e antipasmódica, glicosídeos esteroidais com atividade anti-inflamatória e sesquiterpenoides citotóxicos têm sido isolados de plantas do gênero Vernonia (Maia et al., 2010). Os triterpenos, esteróides, flavonóides e os fenóis foram constituintes encontrados no extrato dessa espécie (Tabela 2), justificando as indicações medicinais empíricas da comunidade para patologias respiratórias, úlcera e câncer, respectivamente, conforme também indicado na literatura (Tabela 1). Estudos feitos com outras espécies desta mesma família Asteraceae sugeriram os flavonóides como marcador quimiotaxonômico (Emerenciano et al., 2005).

Os testes fitoquímicos realizados nos extratos revelaram a presença de vários grupos de metabólitos secundários que podem contribuir para a identificação de marcadores químicos para as espécies estudadas, sendo estes indispensáveis para os testes de qualidade e integridade de fitoterápicos, conforme preconiza a Resolução RDC n. 14/2010 - da Agencia Nacional de Vigilância Sanitária-ANVISA, ao Ministério da Saúde (ANVISA, 2010). Estas substâncias marcadoras características tornam a matéria prima mais conhecida, sendo fator importante para padronização de fitoterápicos, especialmente mediante a grande variabilidade química das plantas medicinais (Vilegas et al., 2009). Nesta perspectiva se tem melhorias no controle farmacognóstico dessas espécies, evitando a adulteração e uso inadequado dessas plantas medicinais pelas. Estas informações são inéditas no Tocantins sendo relevante no âmbito do Cerrado, bioma prioritário para conservação da biodiversidade, visto a possibilidade de futuramente verificar atividades biológicas in vitro dessas espécies, direcionadas pela presença de grupos de metabólitos secundários de interesse.

\section{CONCLUSÃO}

As indicações terapêuticas empíricas, informadas pela comunidade rural, sinalizaram para a ação biológica e farmacológica dos constituintes fitoquímicos presentes nos extratos das plantas estudadas. As espécies já foram estudadas isoladamente em investigações anteriores, porém, a abordagem ora apresentada constitui-se acervo complementar sobre um grupo de plantas medicinais nativas consideradas potenciais para novos estudos e ainda não investigadas para algumas finalidades de relevante interesse social e ecológico, como doenças endêmicas negligenciadas, ainda persistentes na região norte do País, inclusive no estado do Tocantins, e aplicações no âmbito da agroecologia. As informações direcionam estudos futuros para verificação da atividade biológica dessas plantas com base na presença dos constituintes fitoquímicos relevantes, como compostos fenólicos, flavonoídicos e terpenos com potencial antimicrobiano, antioxidante e controle de insetos. Revela informações inéditas no âmbito do Estado do Tocantins, localizado no Bioma

Rev. Bras. PI. Med., Campinas, v.15, n.4, supl.I, p.692-707, 2013. 
Cerrado considerado um dos últimos "hotspots" mundiais, sendo prioritário para conservação da biodiversidade. O resultado positivo dos testes fitoquímicos realizados nos extratos de espécies medicinais, presentes na flora nativa do Tocantins, Estado localizado ao centro do País e estratégico para escoamento de recursos produtivos como matéria prima medicinal, sinalizam para possíveis marcadores químicos para as espécies estudadas e amplia o conhecimento da flora medicinal de Áreas de Reserva Legal, importantes de conservação em assentamentos rurais. Estes marcadores são indispensáveis para validação das plantas medicinais, usos populares mais seguro e para testes de qualidade e integridade de fitoterápicos, possibilitando melhor controle farmacognóstico dessas espécies.

\section{AGRADECIMENTOS}

Este estudo foi apoiado pela FINEP, Conselho Nacional de Desenvolvimento Científico e Tecnológico - CNPq, Secretaria da Ciência, Tecnologia, Inovação e Desenvolvimento Econômico do Estado do Tocantins, Centro Universitário UnirG e UFT (Estruturante $n^{\circ}$ 01.08.0453.00/2008); integrado ao Programa Doutoral em Biologia e Ecologia das Alterações Globais/Área: Biologia e Ecologia Tropical, Departamento de Biologia/ Universidade de Aveiro, Portugal, em convênio com o Estado (Fundação de Amparo a Pesquisa do Tocantins - bolsa de estudos de doutorado para a $1^{\text {a }}$ autora).

\section{REFERÊNCIA}

Agência Nacional de Vigilância Sanitária (ANVISA). Resolução de Diretoria Colegiada -RDC n¹4, de 31 de março de 2010. Dispõe sobre o registro de medicamentos fitoterápicos. Diário Oficial da União, Poder Executivo, Brasília - DF, 5 abr. 2010. Disponível em: http://www.anvisa.gov.br/e-legis. Acesso em: mai de 2012.

ANDRADE, B.S.B. et al. Plantas medicinais e tóxicas. In: III SIMPÓSIO SOBRE RECURSOS NATURAIS E SOCIOECONÔMICOS DO PANTANAL, 2000, Corumbá. Anais... Corumbá, 2000.

ALBUQUERQUE, U.P; HANAZAKI, N. As pesquisas etnodirigidas na descoberta de novos fármacos de interesse médico e farmacêutico: fragilidades e perspectivas. Revista Brasileira de Farmacognosia, v.16, p.678-689, 2006.

ALVES, E. O. et al. Levantamento etnobotânico e caracterização de plantas medicinais em fragmentos florestais de Dourados-MS. Ciência agrotecnológica, Lavras, v.32, n.2, p.651-658, 2008.

ARJONA, F.B.S et al. Aspectos etnobotânicos e biogeografia de espécies medicinais e/ou rituais comercializadas no mercado de madureira, RJ.
Caminhos de Geografia, v.8, n.23, p.41-50, 2007.

ARDISSON, L. et al. Preparação e caracterização de extratos glicólicos enriquecidos em taninos a partir das cascas de Stryphnodendron adstringens (Mart.) Coville (Barbatimão). Revista Brasileira de Farmacognosia, v. 12, n.1, p. 27-34, 2002.

BARBOSA-FILHO, J.M. et al. Plants and their active constituents from South, Central, and North America with hypoglycemic activity. Revista Brasileira de Farmacognosia, v. 15, n. 4, p. 392-413, 2005.

BASTOS, E.M.A.F. et al. In vitro study of the antimicrobial activity of Brazilian propolis against Paenibacillus larvae. Journal of Invertebrate Pathology, n.97, p.273-281, 2008.

BRAGA, F.C de. Pesquisa Fitoquímica. In: Leite, J.P.V. Fitoterapia: bases científicas e tecnológicas. 1. ed. São Paulo: Editora Atheneu, 2009, 328p.

BRUNETON, J. Farmacognosia. 2. ed. Zaragoza: Acribia, 2001. 1099p.

CHAVES, M.H. et al. Fenóis totais, atividade antioxidante e constituintes químicos de extratos de Anacardium occidentale L., Anacardiaceae. Revista Brasileira de Farmacognosia, v. 20, n. 1, p. 106-112, 2010.

COELHO, F. B. R; SANTOS, M. G. Plantas medicinais utilizadas pela comunidade de Mumbuca JalapãoTO: Um estudo etnofarmacológico. 2008. Pesquisa e Conservação do Cerrado. Porto Nacional. (www. pequi.org.br/Coelho_\&_Santos.pdf). Acesso em: 05 de Mar. 2011.

CORREAA, M. P. Dicionário das plantas úteis do Brasil e das exóticas cultivada. Rio de Janeiro: Ministério da Agricultura/IBDF, BR. 4, 1984. p.765.

CORREAA, J.C.R.; SALGADO, H.R.N. Atividade inseticida das plantas e aplicações: revisão. Revista Brasileira de Plantas Medicinais, v.13, n.4, p.500-506, 2011.

COSTA, G. M. et al . An HPLC-DAD method to quantification of main phenolic compounds from leaves of Cecropia Species. Journal Brazil Chemical Society, São Paulo, v. 22, n. 6, jun. 2011.

CRONQUIST, A. An integrated system of classification of flowering plants. New York: Columbia University. p.1260, 1981.

CONSOLINI, A.E.; MIGLIORI, G.N. Cardiovascular effects of the South American medicinal plant Cecropia pachystachya (ambay) on rats. Journal of Ethnopharmacology, v.96, p.417-422, 2005.

CUNHA, E. V. L.; BARBOSA FILHO, J.M. Alcalóides derivados do núcleo isoquinolinico. In: YUNES, R.A.; CECHINEL FILHO, V. Química de produtos naturais, novos fármacos e a moderna farmacognosia. 2 ed. Itajaí: Universidade do Vale do Itajaí, 2009. p.281 - 319.

DANTAS, J. D. P. Contribuição científica à medicina tradicional dos Tapebas do Ceará: Astronium urundeuva (Allemão) Engl. - (aroeira-do-sertão). 2003. 37p. Monografia (Graduação, Universidade Estadual do Ceará), Ceará, Fortaleza.

DELPRETE, P. G.; SMITH, L. B.; KLEIN, R. M. Flora ilustrada catarinense: Rubiáceas. Itajaí: Herbário Barbosa Rodrigues, v.2, p.842, 2005.

EMERENCIANO, V.P. et al. In: VERDI, L.G; BRIGHENTE, I.M.C; PIZZOLLATTI, M.G, Gênero Baccharis (Asteraceae): aspectos químicos, econômicos e biológicos. Química Nova, v.28, n.1, p.85-94, 2005.

Rev. Bras. PI. Med., Campinas, v.15, n.4, supl.I, p.692-707, 2013. 
FILIZOLA, L.R.S. Estudo Farmacognóstico de Vernonia Brasiliana (L) Druce (Asteraceae) e determinação de sua atividade Biológica. 2003. 104 p. Dissertação (Mestrado - Área de Concentração em Ciências Farmacêuticas) - Programa de Pós-graduação em Ciências Farmacêuticas, Universidade Federal de Pernambuco, Recife.

FISCHER, D.C.H. Caracterização farmacológica da droga e do extrato fluido de limoeiro-bravo - Siparuna apsiosyce (Martius) A. 1997. 235p. Dissertação (Mestrado, Universidade de São Paulo) São Paulo.

FISCHER, D.C.H. et al. Essential oils from fruits and leaves of Siparuna guianensis (Aubl.) Tulasne from Southeastern Brazil. Journal of Essential Oil Research, v.17, n.1, p.101-4, 2005.

FISCHER, D.C.H., GONÇALVES, M.I., OLIVEIRA, F., ALVARENGA, M.A. Components of Siparuna apiosyce. Fitoterapia. Milano, v.70, n.3, p.322-323, 1999.

FOGLIO, M.A et al. Plantas Medicinais como Fonte de Recursos Terapêuticos: Um Modelo Multidisciplinar. 2006. In: Construindo a História dos Produtos Naturais. MultiCiência. CPQBA/UNICAMP. Disponível em: http:// www.multiciencia.unicamp.br/artigos_07/a_04_7.pdf. Acesso em:12 de mai de 2012.

FORMISANO, C. et al. Chemical composition and antimicrobial activity of the essential oil of Phlomis ferruginea Ten. (Lamiaceae) growing wild in Southern Italy. Flavour Fragrance Journa, v.21, p.848-851, 2006.

FRUTUOSO, V.S. et al. Analgesic and anti-ulcerogenic effects of a polar extract from leaves of Vernonia condensata. Plant Medicinal, v.60, n.1, p. 21-25, 1994.

GONÇALVES, A.L. et al. Estudo comparativo da atividade antimicrobiana de extratos de algumas árvores nativas. Inst. Biol. São Paulo. v.72, n.3, p.353-358, 2005.

GUARIM-NETO, G.; MORAIS, R.G. Recursos medicinais de espécies do cerrado de Mato Grosso: um estudo bibliográfico. Acta Botanica Brasilica, v.17, n.4, p.561584, 2003.

HASLAM, E. Plant Polyphenols, Vegetable Tannins Revisited. Cambridge University Press, Cambridge,1989. 230p.

IKEDA, Y.; MURAKAMI, A.; OHIGASHI, H. Ursolic acid: na anti- and pro-inflammatory triterpenoid. Molecular Nutrition \& Food Research, v.52, p. 26-42, 2008.

JACOMASSI, E. et al. Morfoanatomia e histoquímica de Brosimum gaudichaudii Trécul (Moraceae). Acta Botanica Brasilica, v. 2, n. 3, p. 575-597, 2007.

JAYAPRAKASAM, B. et al. Terpenoids from Stinking toe (Hymenaeae courbaril) fruits with cyclooxygenase and lipid peroxidation inhibitory activities. Food Chemistry, v.105 p.485-490, 2007.

KAMATH, V.; RAJINI, P. S. The efficiency of cashewnut (Anacardium occidentale L.) skin extract as a free radical scavenger. Food Chemistry, v. 103, n. 2, p. 428-433, 2007.

LEITE, J.P.V. Química dos produtos naturais: Uma abordagem Biossintética. In: Leite, J.P.V. Fitoterapia: bases científicas e tecnológicas. 1. ed. São Paulo: Editora Atheneu, 2009, 328p.

LEÃO, A. R. et al. Avaliação clínica toxicológica preliminar de Viticromin ${ }^{\circledR}$ em pacientes com vitiligo. Revista
Eletrônica de Farmácia, v. 2, n. 1, p.15-23, 2005.

LOPES, T. C. da, L. et al. Avaliação moluscicida e perfil fitoquímico das folhas de Caryocar brasiliense Camb. Cad. Pesq., São Luís, v. 18, n. 3, p.23-30, 2011.

LÓPEZ, C.A.A. Considerações gerais sobre plantas medicinais. Ambiente: Gestão e Desenvolvimento, v.1, p.19-27, 2006.

LORENZI, H.; MATOS, F.J.A. Plantas medicinais do Brasil: nativas e exóticas cultivadas. 4.ed. Nova Odessa-SP: Instituto Plantarum, 2002, 512p.

MAIA, A.I.V. et al. Óleos essenciais das folhas de Vernonia Remotiflora e Vernonia Brasiliana: composição química e atividade biológica. Química Nova, v.33, n.3, p.584586, 2010.

MATOS, F.J. A. Introdução à Fitoquímica Experimental. 2. ed. Fortaleza: Edições UFC, 1997, 141p.

MELLO, J. C.P.; SANTOS, S. C. Taninos. In: SIMÕES, C.M.; SCHENKEL, E. P.; GOSMANN, G.; MELLO, J. C.P.; MENTZ, L.A.; PETROVICK, P.R. Farmacognosia: da planta ao medicamento. 3 ed. Porto Alegre: Ed.UFGRS/Ed.UFSC, 2001. cap. 24, p.517-543.

MENDES, L.P.M. et al. Atividade Antimicrobiana de Extratos Etanólicos de Peperomia pellucida e Portulaca pilosa. Revista de Ciências Farmacêuticas Básica e Aplicada, v.32, n.1, p.121-125, 2011.

MENDONÇA, F.A.C. et al. Activities of some Brazilian plants against larvae of the mosquito Aedes aegypti. Fitoterapia, v.76, p.629-636, 2005.

MIDDLETON JUNIOR, E. et al.The effects of plant flavonoids on mammalian cells: implications for inflammation, heart disease, and cancer. Pharmacol Rev, v. 52, n. 4, p. 673-751,2000.

MIRANDA, G.S. et al. Atividade antibacteriana in vitro de quatro espécies vegetais em diferentes graduações alcoólicas. Revista Brasileira de Plantas Medicinais, v.15, n.1, p.104-111, 2013.

MORAIS, S.M. et al. Plantas medicinais usadas pelos índios Tapebas do Ceará. Revista Brasileira de Farmacognosia, v.15, n.2, p.169-177, 2005.

MONTEIRO, J.M. et al. The effects of seasonal climate changes in the Caatinga on tannin levels in Myracrodruon urundeuva (Engl.) Fr. All. and Anadenanthera colubrina (Vell.) Brenan. Brazilian Journal of Pharmacognosy, v.16, p.338-344, 2006.

MUSCHIETTI, L.V.; MARTINO, V.S. Atividades biológicas dos flavonóides naturais. In: YUNES, R.A.; CECHINEL FILHO, V. Química de produtos naturais, novos fármacos e a moderna farmacognosia. 2 ed. Itajaí: Universidade do Vale do Itajaí, 2009. p.189-218.

NOGUEIRA, R.T. et al. Clerodane-type diterpenes from the seed pods of Hymenaea courbaril var. stilbocarpa. Phytochemistry, v.58, n.8, p.1153-1157, 2001.

NOGUEIRA, M. E. I. et al. Investigation of genotoxic and antigenotoxic activities of Melampodium divaricatum in Salmonella typhimurium. Toxicology in vitro , v.20, p.361-366, 2006.

OKEKE, M.I et al. Evaluation of extracts of the root of Landolphia owerrience for antibacterial activity. Journal Ethnopharmacol, v.78, p.119-127, 2001.

OLAJIDE, O.A. et al. Effects of Anacardium occidentale stem bark extract on in vivo inflammatory models. Journal of Ethnopharmacology, v. 95, p. 139-142, 2004.

Rev. Bras. PI. Med., Campinas, v.15, n.4, supl.I, p.692-707, 2013. 
OLIVEIRA, F.C.S; BARROS, R.F.M; MOITA NETO, J.M. Plantas medicinais utilizadas em comunidades rurais de Oeiras, semiárido piauiense. Revista Brasileira de Plantas Medicinais,v.12, n.3, p.282-301, 2010.

OLIVEIRA, D.G. et al. Antimycobacterial activity of some Brazilian indigenous medicinal drinks. Journal of Basic and Applied Pharmaceutical Sciences, v.28, n.2, p.165-169, 2007.

OLIVEIRA, L.G. et al. Inibidores de proteases encontrados em sementes de Caesalpinia echinata (pau-brasil) isolamento e caracterização do inibidor de tripsina. Revista Brasileira de Farmacognosia, v.12, p.72-74, 2002.

ONO, M. et al. Three new monoterpenoids from the fruit of Genipa americana. Chemical Pharmaceutical Bulletin, v55, n.4, p.632-634, 2007.

OLIVEIRA, F.; SAITO, M. L. Alguns vegetais brasileiros empregados no tratamento da diabetes. Revista Brasileira de Farmacognosia, v. 2, n. 4, p. 170-196, 1989.

PANIZZA, S. Plantas que curam: cheiro de mato. 15 ed. São Paulo: IBRASA. p.279, 1997.

PÉREZ-GUERRERO, C. et al. A pharmacological study of Cecropia obtusifolia siBertol aqueous extract. Journal of Ethnopharmacology, p.76, n.3, p.279-284, 2001.

PINTO, A.S et al. Flavonóides. Biotecnologia \& desenvolvimento. n.17. p.18-22, 2000.

PINHO, L. et al. Atividade antimicrobiana de extratos hidroalcoolicos das folhas de alecrim-pimenta, aroeira, barbatimão, erva baleeira e do farelo da casca de pequi. Ciência Rural, v.42, n.2, p.326-331, 2012.

Instituto de Colonização e Reforma Agrária - INCRA. Instituto de Desenvolvimento Rural do Estado do Tocantins - RURALTINS. Plano de Desenvolvimento do Assentamento Vale Verde. 2004. 75p. Documentos. PORTO, K.R.A. et al. Atividade larvicida do óleo de Anacardium humile Saint Hil sobre Aedes aegypti (Linnaeus, 1762) (Diptera, Culicidae). Revista da sociedade Brasileira de Medicina Tropical, v.41, p.586-589, 2008.

POZETTI, G.L. Brosimum gaudichaudii Trecul (Moraceae): da planta ao medicamento. Revista de ciências farmacêuticas básica e aplicadas.v.6. n.3. p.159166. 2005.

REVILLA, J. Plantas da Amazônia: oportunidades econômicas e sustentáveis. 2. ed. Manaus: Programa de Desenvolvimento Empresarial e Tecnologia. p.405. 2001.

ROBBERS, J.E.; SPEEDIE, M.K.; TYLER, V.E. Farmacognosia e Farmacobiotecnologia, 1. ed. São Paulo: Editorial premier, 1997. 372p.

ROCHA, W. S. et al. Compostos fenólicos totais e taninos condensados em frutas nativas do cerrado. Revista Brasileira de Fruticultura, v. 33, n. 4, p. 1215-1221, 2011.

RODRIGUES, V.E.G.; CARVALHO, D.A. Levantamento etnobotânico de plantas medicinais no domínio do cerrado na região do Alto Rio Grande - Minas Gerais. Ciência e Agrotecnologia, v.25, n.1, p.102-123, 2001. SANTOS, M.R.A.; LIMA, M.R. Levantamento dos recursos vegetais utilizados como fitoterápicos no município de Cujubim, Rondônia, Brasil. Boletim de Pesquisa e Desenvolvimento, 1 ed., Embrapa Rondônia, 2009.
Disponível em: http://www.cpafro.embrapa.br/media/ arquivos/publicacoes/62_recursosvegetais_fitoterapia. pdf. Acesso em: 15 de abr 2013.

SANCHES, A.C.C. et al. Antioxidant and antifungal activities of extracts and condensed tannins from Stryphnodendron obovatum Benth. Revista Brasileira de Ciências Farmacêuticas, v.41, n.1, p.101-107, 2005.

SANT'ANNA-SANTOS, B. F et al. Anatomia e histoquímica das estruturas secretoras do caule de Spondias dulcis Forst. F. (Anacardiaceae), Revista Árvore, Viçosa-MG, v.30, n.3, p.481-489, 2006.

SCHIMITZ, W. et al. O chá verde e suas ações como quimioprotetor. Semina: Ciências Biológicas e da Saúde, Londrina, v. 26, n. 2, p. 119-130, jul./dez. 2005.

SILVA, J.G. et al. Atividade antimicrobiana do extrato de Anacardium occidentale L. em amostras multiresistentes de Staphylococcus aureus. Revista Brasileira de Farmacognosia, v.17, n.4, p. 572-577, 2007.

SILVA, N.L.A. et al. Triagem fitoquímica de Plantas do Cerrado da Área de Proteção Ambiental Municipal do Inhamum, Caxias, Maranhão. Scientia Plena, v.6, n.2, p.1-17, 2010.

SILVA, S. M. F. Q. et al. Atividade in vitro de extratos brutos de duas espécies vegetais do cerrado sobre leveduras do gênero Candida. Ciênc. saúde coletiva, Rio de Janeiro, v. 17, n. 6, jun. p.1649-1656. 2012.

SIMÕES, C.M.O. et al. Farmacognosia: da planta ao medicamento. 5. ed. Porto Alegre/Florianópolis: Editora da UFSC, 2004. 1102p.

SOARES, J.D.A.H. et al. Atividade tripanocida in vivo de Stryphnodendron adstringens (barbatimão verdadeiro) e Caryocar brasiliense (pequi). Revista Brasileira de Farmacognosia, v.12, p.01-02, 2002a.

SOARES, S.E. et al. Ácidos fenólicos como antioxidantes. Revista de Nutrição, v.15, n.1, p.71-81, 2002b.

SOUZA, J.N.S. et al. Identification and antioxidant activity of several flavonoids of Inga edulis leaves. Journal of the Brazilian Chemical Society, v.18, p.1276-1280. 2007.

SOUZA, C.D.; FELFILI, J.M. Uso de plantas medicinais na região de Alto Paraíso de Goiás, GO. Acta Botanica Brasílica, v.20, n.1, p.135-142, 2006.

SOUZA, R.K.D.; MENDONÇA, A.C.A. M.; SILVA, M. A. P. Aspectos etnobotânicos, fitoquímicos e farmacológicos de espécies de Rubiaceae no Brasil. Revista Cubana de Plantas Medicinais, v.18, n.1, p.140-156, 2013.

SOUZA, J.N.P et al. Bioprospecção das atividades antioxidante e antimicrobiana de espécies vegetais medicinais coletadas em Ouro Preto-MG. Revista Eletrônica de Farmácia, Vol. X, n.1, p.01 - 15, 2013.

SPARG, S.G.; LIGHAT, M.E.; VAN STADEN, J. Biological activities and distribution of plant saponins. Journal of Ethnopharmacology, v. 94, n. 2-3, p. 219-243, 2004.

TANAE, M.M. et al. Chemical standardization of the aqueous extract of Cecropia glaziovii Sneth endowed with antihypertensive, bronchodilator, antiacid secretion and antidepressant-like activities. Phytomedicine, v.14, p.309-313, 2007.

TEIXEIRA, S.A.; MELO, J.I.M. Plantas medicinais utilizadas no município de Jupi, Pernambuco, Brasil. IHERINGIA, Série Botânica., Porto Alegre, v.61, n.1-2, p.5-11, 2006. 
TROX et al. Catechin and epicatechin in testa and their association with bioactive compounds in kernels of cashew nut (Anacardium occidentale L.). Food Chemistry, v. 128, Issue 4, 15, p. 1094-1099, 2011.

VALENTINI, C.M.A et al. Variação anual do rendimento e composição química dos componentes voláteis da Siparuna guianensis Aublet. Química Nova, v.33, n.7, p.1506-1509, 2010a.

VALENTINI, C. M. A. et al. Siparuna guianensis Aublet (negramina): uma revisão. Revista Brasileira Plantas Medicinais, Botucatu, v.12, n.1, p.96-104, 2010 b.

VARANDA et al. Genotoxicity of Brosimum gaudichaudii measured by the Salmonella/microsome assay and chromosomal aberrations in $\mathrm{CHO}$ cells. Journal of Ethnopharmacology, v.81, p.257-264, 2002.

VASCONCELOS, M. C. A. et al. Avaliação de atividades biológicas das sementes de Stryphnodendron obovatum Benth. (Leguminosae). Revista Brasileira de Farmacognosia, v.14, n.1, p.121-127, 2004.

VIANA, G.S.B. et al. Aroeira-do-sertão (Myracrodruon urundeuva Fr. All.) - Estudo botânico, farmacognóstico, químico e farmacológico. 1995. 164p. Fortaleza: Universidade Federal do Ceará.
VIANA, G.S.B. et al. Analgesic and antiinflammatory effects of the tannin fraction from Myracrodruon urundeuva Fr. All. Phytotherapy Research, v.11, p.118-122, 1997.

VIANA, G.S.B. et al. Analgesic and antiinflammatory effects of chalcones isolated from Myracrodruon urundeuva Allemao. Phytomedicine, v.10, n.2-3, p.189195, 2003.

VIEIRA, R.F. et al. Frutas nativas da região Centro-Oeste do Brasil. 1. ed. Brasília: Embrapa Recursos Genéticos e Biotecnologia, 2006. 320p. Disponível em: <www. cenargen.embrapa.br/publica/trabalhos/livro_frutas_ nativas.pdf>. Acesso em: 18 maio de 2011.

VILEGAS, W. et al. Coumarins from Brosimum gaudichaudii. Journal Natural Products, v. 56, n. 3, p. 416-417, 1993.

VILEGAS, W.; CARDOSO, C.A.L; QUEVEDO, A.E.P. Controle químico de qualidade de fitoterápicos e plantas medicinais. In: YUNES, R.A.; CECHINEL FILHO, V. (orgs). Química de Produtos Naturais, novos fármacos e a moderna farmacognosia. 2. ed., Itajaí: Universidade do Vale do Itajaí, 2009, p. 163-188.

YUNES, R. A. Plantas medicinais sob a ótica da moderna química medicinal. 1 ed. Chapecó: Editora Argos, 2001. 523p. 